\title{
Work Practices, Nomadicity and the Mediational Role of Technology
}

\author{
Luigina Ciolfi ${ }^{1} \&$ Aparecido Fabiano Pinatti de Carvalho ${ }^{2}$ \\ ${ }^{1}$ Communication and Computing Research Centre-C3RI, Sheffield Hallam University, Cantor Building, \\ 153 Arundel Street, Sheffield S1 2NU, UK (Phone: +44-114-2256826; E-mail: L.Ciolf@shu.ac.uk); \\ ${ }^{2}$ Multidisciplinary Design Group, Vienna University of Technology, Favoritenstraße 9-11/187, A-1040 \\ Vienna, Austria (E-mail: Fabiano.Pinatti@tuwien.ac.at)
}

\section{Advancing the understanding of nomadicity}

Over the past number of years new forms of work have emerged and developed, particularly in the service and education sector, and, more broadly, with regards to information work. One of the key characteristics of such forms of work, and particularly information work, is the potential (and often the need) for nomadic practices, since workers mainly deal with something that can be represented digitally and taken to or accessed from different locations. In other words, work activities in certain professional contexts can and often must be detached from stable premises, and performed when and where it suits the workers' needs (Davis 2002). In fact, increasing attention is being paid to what is here called modern nomadicity and that involves engaging with work activities across different locations based on the availability of the resources that are necessary for accomplishing them (de Carvalho et al. 2011). Several studies have addressed issues related to nomadic practices and the design of technologies to support those involved with them, addressing a broad range of issues varying according to the particular field of enquiry within which they were conducted. For instance, in Ubiquitous Computing and Business Information Systems, researchers have been addressing the development of mobile and pervasive technologies and technological affordances, which can be translated into specific performances when used in individual and organisational practices (Weiser 1993; Kleinrock 1996; Gorlenko and Merrick 2003; Sørensen 2011). In turn, HCI researchers have been concerned with the usability of portable devices and the development of methods for accurately assessing it (Weiss 2002; Coursaris and Kim 2006; Johansson et al. 2006). In CSCW, the focus has been directed towards the use of computing technologies to mediate social and collaborative activities in and across different locations and towards an understanding of how different spaces are inhabited and transformed in places as work gets accomplished, i.e. a concern with 
issues to do with articulation and mobilisation work as well as with place-making activities (Perry et al. 2001; Ciolfi et al. 2005; Bogdan et al. 2006; Rossitto 2009).

Notwithstanding this body of research on the topic, there is room still for in-depth investigation of nomadic work/life practices. As previously noted, there are several nuances involved in understanding the notion of nomadicity, and the different definitions of nomadicity found in the literature are proof of that. For instance, Su and Mark (2008) define nomadicity as an extreme form of mobile work that encompasses people being constantly on the move, usually travelling long distances, working wherever they happen to be, and carrying their resources with them so that they can set up temporary workplaces. Rossitto and Eklundh (2007) characterise the concept as a work condition that entails (a) the absence of a stable workplace where work activities can be carried out and (b) the experience of a complex system of environmental, temporal and technological discontinuities. Bean and Eisenberg (2006) consider nomadicity as a "radical new form of work" that is based on the workers' mobility both at and away from their company, on paperless operations (i.e. use of digital resources for work) and on integrated technological platforms. Kleinrock (1996) conceptualises it in terms of access to technological resources anytime/anywhere.

As evident in the aforementioned definitions, nomadicity is frequently associated with mobility and work at multiple locations. Thus "nomadicity" and "mobility", as well as their adjective forms, e.g. "nomadic work" and "mobile work", often end up being used interchangeably (Rossitto 2009). In addition to these terms, expressions such as "flexible work", "fluid work" and "mobile telework" (among others) can also be found in the literature (Kleinrock 1996; Perry et al. 2001; Kakihara et al. 2002; Bødker et al. 2003; Hislop and Axtell 2007; Meerwarth 2008); all these terms are somehow associated with the same thing: developing work activities in and across several locations besides the "official", stable workplace (e.g. the office) with the help of computing technologies to mobilise work resources (de Carvalho 2013).

Another reason to make a distinction between these two terms is linked to their analytical and methodological implications (Rossitto 2009). One possible way to differentiate the two notions is to regard mobility as the physical movement of people between locations (Sørensen et al. 2005). Thus, mobile work would refer, for example, to jobs that encompass people's moving across locations as part of the accomplishment of their work assignments, i.e. they do not stop somewhere to accomplish their tasks, their work is accomplished as they move through different sites (e.g. sailors, drivers, pilots, postmen, and so forth) (ibid). On the other hand, nomadicity refers to something that encompasses a complexity that goes beyond the simple movement of people (Bogdan et al. 2006): it spans over the mobility of resources that allow workers to set up their workplaces in different locations and to perform their productive activities. Thus it involves both the movement of people and things but also the work in preparing for 
such movement and following the movement in creating conditions to engage with work and life activities.

In fact, nomadicity is directly related to the notion of fluidity discussed by Kakihara et al. (2002). What de Carvalho terms the "mobility of the workplace" (de Carvalho 2013, p. 3), which is central to nomadicity, happens as a result of the frequent negotiations of on-going fluid interactions in and across different sites where work gets accomplished. Here we establish a clear parallel between nomadism and nomadicity:

(...) Like pastoral nomads move their households to locations where they can find green pasture for their herds and water for their crops, modern nomads move their workplace to locations where they can find resources such as time, space, privacy, other people, to name but a few. (de Carvalho 2013: p. 138, emphasis added)

In order to avoid confusion, we point out that, here, the mobility of the workplace does not infer the relocation of the complete workplace setting to another site: instead, the mobility of the workplace is understood as the result of the mobilisation of different work resources, e.g. laptops, mobile phones, printouts, and other assets that are used to set up temporary workplaces in assorted locations where work is achieved. Therefore, the notion of workplace as something bound to a single location is extended to include a more fluid facet, which can particularly be observed in knowledge-based work (Kakihara et al. 2002; Meerwarth 2008; Rossitto 2009; de Carvalho 2013). This becomes evident in the articles featured in this special issue.

Whilst the articles of this special issue confirm that there are some jobs that demand that people move to different locations and accomplish their work tasks from these locations, i.e. inherent multi-located work (e.g. Humphry 2014), they suggest that there are also certain types of work that are not strictly nomadic but that allow people to engage in work activities in different locations, i.e. the flexible work (e.g. Liegl 2014), and there are different motivations that lead people to articulate work practices in different locations (e.g. Rossitto et al. 2014 and Liegl 2014). This illustrates how nomadicity, as a notion, can be associated with a spectrum of motivational forces ranging from choice (e.g. when one decides to go somewhere to work because the venue would offer her/him comfort), through opportunity (e.g. when one decides to engage in work in locations where they have not planned to do so because resources such as time or collaborators become conveniently available), to obligation (e.g. when one must relocate to a specific site to conduct work, because certain resources - such as a particular piece of equipment - can only be found there). This association has been explored in detail by de Carvalho (2013), whose findings suggest that nomadicity is not to do with a single category of work, but with a dynamic and emergent process that leads to the accomplishment of work at assorted locations. This process is reconfigured 
according to the ways in which people think of their work/life, strategise about it and react in situations where tasks cannot be accomplished as planned.

In this introduction, we aim to provide an overview of current perspectives on nomadicity and to elaborate on what we suggest to be a more nuanced account of the notion, which the articles in the special issue contribute to. We do so by reviewing relevant literature on the matter and by introducing and linking the articles in this special issue. Our goal is to provide a clearer understanding of past and present contributions on the matter and to raise questions to be addressed by future research.

\section{Framing nomadicity}

Different frames may be applied to understanding nomadicity (Rossitto 2009). Four prominent perspectives can be found in the literature, and they are to do with a technology-centred, a practice-centred, a place-centred and a work-life boundary-centred approach to define, explore and understand nomadicity and the issues surrounding it (de Carvalho 2013). These frames are not mutually exclusive: there are overlaps between them and studies that prioritise one of these views may address issues of the other three. However, the important thing is that all of them address nomadicity in the same sense, i.e. that of accomplishing work in and across different locations with the help of computing technologies, even though not all of them use "nomadicity" as the overall term to describe this. The frames we identified are practical categories that represent the variety of concerns that characterise the study of nomadicity and the issues that have been privileged in particular subsets of the literature.

\subsection{Technology-centred frame: nomadicity as "system support"}

The technology-centred approach is probably the earliest perspective found in the literature framing nomadicity. In his seminal paper "Nomadicity: Anytime, Anywhere in a Disconnected World", Kleinrock (1996) discussed the development of a technological architecture that would allow for anytime/anywhere access to information and technological resources, coining the term nomadic computing alluding to all technologies that could enable or empower the mobility of people and of digital artefacts.

A common definition for nomadicity in studies that conform to this perspective is that of activities made possible by a "support system" that provides computing and communication capabilities and services to people as they move from place to place and engage in work at those places. According to Kleinrock (2001), such a support must be provided in a way that is "transparent, integrated, convenient and adaptive" (p. 42).

The technology-centred perspective on nomadicity is directly related to and somehow a progeny of studies in Ubiquitous Computing that aim at the development 
of mobile and pervasive computing technologies to be used in different contexts (Weiser 1993; Makimoto et al. 2001; Lyytinen and Yoo 2002; Sørensen 2011). Thus, the research agenda of those who adopt this perspective is the development of computerised tools and nomadic computing environments to support people who work in and across different locations (see the research commentary by Lyytinen and Yoo 2002). The assumptions here are that computer technologies can offer people location independence; reduce the number of tangible artefacts to be carried; provide instant information retrieval; allow for swifter data processing and reduce the cost associated with engaging in work in multiple locations (Makimoto and Manners 1997; Kleinrock 2001). Studies within this frame usually approach technical issues of connectivity, network-based applications, context-aware systems, technological and environmental infrastructure, technology pervasiveness, mobile technology use and so forth. Most importantly, they discuss how these elements may serve the purpose of supporting people who work in and across different locations (Kindberg and Barton 2001; Breure and van Meel 2003; Kakihara and Sørensen 2004; Pica et al. 2004; Cousins and Robey 2005; Demiris and Ioannidis 2005; Oulasvirta and Sumari 2007).

Two major concerns for these researchers are the usability of the computer technologies available for nomadicity and the user experience that they provide (Gorlenko and Merrick 2003; Harper 2003; York and Pendharkar 2004; MurraySmith 2009). A common finding is that, when issues inherent to nomadicity are not well understood and considered during the design phase, new technologies will not work in the way they were intended to (Luff and Heath 1998).

Beside the development and evaluation of computer technologies for nomadicity, studies within this frame also pay attention to issues such as the use and management of different technologies available for different contexts of interaction and different activities (Vartiainen 2006; Rossitto and Eklundh 2007). For instance, people may want to use different technologies for maintaining the boundaries between personal and professional lives (Cousins and Robey 2005). Moreover, keeping data scattered across multiple devices may also be a strategy for data security, i.e. for avoiding data to be accessed by unwanted people, or for operational safety, i.e. for being able to continue working in case one device fails (Oulasvirta and Sumari 2007). However, as Oulasvirta and Sumari (2007) observe, management of different devices may be problematic, demanding physical and mental effort with activities that are not the focus of the work.

Whilst studies conducted under this perspective are concerned with developing and providing technological support, they do not take into account the fact that nomadicity is not limited to the system support used by people in different places and in different contexts of interaction. Even though some authors go on to investigate and understand how specific tasks are accomplished on the move so that they can elicit the requirements for system development, they do not investigate and examine how the other activities that people develop as they are working on a specific task are related to or affect the task in hand, which 
motivations people have to engage in an activity in a location rather than in another, and so on. In summary, many of the contextual aspects as well as the social aspects regarding the use of the proposed technologies are left out of such analyses.

\subsection{Practice-centred frame: nomadicity as a multifocal strategy}

The second frame we identify abstracts the use of technologies and the practices involved in nomadicity into a nomadic strategy. Researchers adopting this position pay attention not only to the structured work activities that people have to perform and get paid for, but also to all the activities they need to complete in order to mobilise their work and to get work accomplished in and across different locations.

Since nomadicity is inherently mediated by computer technologies, their role in the development of these activities emerges strongly from these studies. Here we use the term "mediate" in reference to the process of acting as a medium or a support for an activity (De Boever and De Grooff 2009, p. 79). As discussed in the previous section, such mediation is usually achieved by means of mobile and/ or networked systems that allow people to be in contact with each other in order to carry out their activities. However, this perspective is not concerned about developing a new piece of technology, but rather with investigating how current technologies fit within the context of human activities. Technologies are seen as tools that serve a greater goal (i.e. accomplishing work at different locations). Eventually, implications for design are drawn with suggestions for the development of new technologies. Hence, this perspective is particularly relevant to $\mathrm{CSCW}$, since one of the main concerns of the field is to understand the mediational role that computer technologies have in work practices and cooperative activities such as collaboration, coordination, awareness mechanisms and information sharing (Schmidt and Bannon 2013).

Within this frame, special attention is paid to the strategies employed by people as they go on to carry out their activities. For instance, drawing on the analysis of the strategy of pastoral nomads in doing their nomadicity, Su and Mark (2008) depict an insightful representation of the strategies employed by people involved in nomadicity. The authors argue that such a strategy can be divided into three categories of practices: assembling actants ${ }^{1}$, seeking resources, and integrating with others. In another study within this frame, Perry et al. (2001) identify four key factors related to nomadicity: planning for the unpredictable; working in "dead time", accessing remote human, technological and informational resources; and monitoring

\footnotetext{
${ }^{1}$ Actant is a term borrowed by Su and Mark (2008) from Actor-Network Theory (Latour 2007) to refer to any asset carried, accessed or contacted by nomads as they go on to set up their temporary workplaces and proceed to conduct their work activities. Mobile phones, laptops, work documents and people are some examples of actants.

2 "Dead time" refers to the time spent in airports, buses, hotels, between work sections.
} 
the activities of remote colleagues. Those four key factors are directly related to the three foci of the nomadic strategy proposed by Su and Mark (2008). For example, when it comes to the assemblage of actants, deciding which resources should be taken when moving the workplace to a different site can be also related to the key factor of preparing for the unpredictable (Perry et al. 2001).

Regarding the search for resources, access to remote technological and informational resources (Perry et al. 2001) is a key factor since a resource must be available in order to be found. In this regard, network connection, different Internet protocols, the World Wide Web and several web-based tools allow people to access digital resources, both technological and informational, that are made available. The spread of broadband connection and the existence of high capacity servers, such as Google Drive accounts and other similar services, made it easy to upload large amount of data that can be, in the same way, downloaded afterwards. Connectivity, as foreseen by Kleinrock (1996), now plays a central role because it makes possible the access of resources anytime/anywhere.

In terms of integrating with others, many technologies allow people to be in contact with other people independently of location. These technologies have made more flexible the choice between synchronous and asynchronous interaction: on the one hand, somebody can have a synchronous chat through an instant messenger or call someone on the other side of the world using a mobile phone. On the other hand, communication can be conducted asynchronously through e-mail. This is an example of how technology can allow for the temporal mobility mentioned by Kakihara and Sørensen (2001).

Integrating with others can refer both to the contact that people working remotely establish with locals in order to be able to make proper use of the infrastructures available on site and to monitoring activities of remote colleagues identified by Perry et al. (2001) as one of the key factors of nomadicity. In regard to the latter, one can keep track of activities in the office asking for daily report emails. Another possibility is to use an on-line interactive tool where people can report their activities.

Although the practice-centred perspective goes further than the technologycentred perspective in investigating the issues surrounding nomadicity, there is still a downside in this approach: it does not fully account for the different locations where work gets accomplished. The difficulties that working in different locations can cause are examined, but movement from and to multiple sites and the implications of moving to different locations to work and the influences of those locations on the work activities are not clearly explored.

\subsection{Place-centred frame: nomadicity as situated work in multiple locations}

The third approach is related to understanding nomadicity as a matter of "work bound to different places" (Rossitto 2009, p.14). This perspective is closely 
associated with CSCW's tradition of investigating the role that spaces and places $^{3}$ play in the development of collaborative work (Harrison and Dourish 1996; Ciolfi et al. 2008).

The focus is on how places are created and experienced as nomadicity unfolds and how work activities are situated: people who engage in nomadicity are constantly making places for their activities out of physical spaces that offer them certain support, in order to carry out their work. This has direct implications on the accomplishment of work (Ciolfi et al. 2005; Murphy et al. 2006; Rossitto and Eklundh 2007).

In fact, place has been considered a practical concern for nomadicity for a long time (Brown and O'Hara 2003; Felstead et al. 2005). As Brown and O'Hara (2003) discuss in their seminal article, place can influence the development of work activities depending on the affordances it provides workers with. At the same time, work can also impact on the construction and experience of place as people go on to modify and configure generic spaces according to their needs so that work can be accomplished there.

Noting such importance, many researchers have invested in advancing the understanding of the relationship between nomadicity and place (e.g. Churchill and Munro 2001; Breure and van Meel 2003; Murphy et al. 2006; Rossitto 2009). Rossitto (2009), for instance, goes on to show how place can be used as a framework to understand nomadicity using the notion of place to guide the data collection and data analysis processes of her study on the effects of nomadicity on collaborative writing activities within groups of students.

Churchill and Munro's (2001) findings, for instance, showed that people tend to appropriate the physical space where they are working by spreading photos and files over it. In the same way, Brown and O'Hara (2003) observations show people appropriating and transforming spaces by using low and high tech artefacts such as laptops, phones, cups, family photos and so forth before starting the actual work.

Actual place-making activities associated with nomadicity and the role of the environment have also been investigated (Harrison et al. 2004; Felstead et al. 2005; Rossitto 2009). Within this literature, it is common to find arguments for the importance of considering the differentiation between the concepts of space and place as such a differentiation impacts on the way tools should be designed to allow for specific kinds of interactions (Harrison and Dourish 1996; Dourish 2006; Ciolfi et al. 2008).

With regard to establishing workplaces across several locations, Perry and Brodie (2006) highlight the importance of taking into consideration the development of tools to allow people to set up their temporary workplaces. In fact, a lot of effort is put into organising and packing things that will be necessary to conduct work at a new location, since such work usually is dependent on information, technological or even

\footnotetext{
${ }^{3}$ Space and place are often treated as different elements. Whilst the former is associated with physical environments (e.g. a room delineated by walls), the latter is usually interpreted according to the views of the phenomenological tradition in which place is considered a physical space invested with human experiences and values where actions and interactions unfold (Brown and O'Hara 2003; Ciolfi 2004; Dourish 2006)
} 
human resources that should be assembled, and brought along to the new location. Also, considerable effort is invested in discovering the resources needed to lay the supportive apparatus down and to make it work (Mark and Su 2010). All these activities developed prior to the formal work is called mobilisation work by Perry and Brodie (2006), i.e. the work done to get nomadicity started.

It is broadly accepted that computer technologies can make mobilisation work easier and more effective (Harrison et al. 2004; Felstead et al. 2005). Actually, several authors mention that the advent and spread of mobile and networked technologies such as laptops, PDAs, mobile and smart phones and so forth, is one of the foundations to the proliferation of nomadic practices, because it allows for the mobility of the workplace to new locations where necessary resources to conduct the work can be found (Kleinrock 1996' 2001; Perry et al. 2001; Wiberg and Ljungberg 2001; Green 2002; Lyytinen and Yoo 2002; Brown and O'Hara 2003; Lilischkis 2003; Kakihara and Sørensen 2004; Demiris and Ioannidis 2005; Su and Mark 2008; Murray-Smith 2009). However, some authors call for caution by pointing to the drawbacks that relying too much on technology can cause (York and Pendharkar 2004; Pica et al. 2004). As York and Pendharkar (2004) put it: "[w]orkers lose time and productivity when they have to reconfigure their work setting and processes to allow mobile technology to support their work" (p.776).

In terms of the role of the environment and the infrastructure available, it is often highlighted that each environment is endowed with specific qualities that may impact upon nomadicity (Brown and O'Hara 2003; Mark and Su 2010) or that may influence the choice of an environment over another (Bogdan et al. 2006). For instance, Rossitto and Eklundh (2007) stress how places are associated with different meanings and how they can afford different interactions and the establishment of specific social relations.

Certain attributes of the environment (e.g. noise level, comfort, public or private space, etc.) are often discussed, and so are the availability of certain resources (e.g. Wi-Fi connectivity, power supply, co-workers, food, among others) and the visibility of the available infrastructure that may impact upon nomadicity (Breure and van Meel 2003; Brown and O'Hara 2003; Lilischkis 2003; Rossitto and Eklundh 2007; Mark and Su 2010).

Although the place-centred approach introduces the role of different locations in nomadicity, which is usually not present in studies framed within the technology-centred or practice-centred approaches, place-centred studies, similarly to the other two perspectives, treat nomadicity as a matter to do exclusively with work, whilst some research suggests that nomadicity is not only to do with the work dimension of life (Goldmacher 2008; Jordan 2008; Meerwarth 2008).

\subsection{Work-life boundary frame: nomadicity as a blurring element of work-life boundaries}

As nomadic practices become more widespread and easier to accomplish, the boundaries between work and non-work are increasingly blurred: it becomes 
easier to "bring work home" and "home to work". Therefore, in order to accurately understand nomadicity, it is often necessary to consider it as something that goes beyond work, something that blurs the distinctions between work and non-work lives (de Carvalho 2013).

Indeed, changes in certain work practices, such as those of knowledge workers, point to a shift from work that is bound to one location and to a fixed temporal structure (for example, the "9 to 5" model, or a shifts system that establishes which hours one should be at work) to more flexible and multi-located nomadic practices (Meerwarth et al. 2008b; Duxbury and Smart 2011; Ciolfi et al. 2012). There is some evidence that this in turn impacts on how people manage the separation or the blurring between work and non-work. Therefore, some researchers have set out to investigate the impacts of engaging in nomadicity in work-life boundaries, making use of a work-life boundary frame to orient their research. Already in 2001, a study by Brodie and Perry (2001) introduced the issue of work-life boundaries. Although the study focused on blue collar workers and the mobility of their work activities, the authors mention that their 'research into mobile professionals identified a slackening off of the traditionally [sic] boundaries between home life and work life' (ibid, p. 26). According to the authors, such workers tended to consider being working wherever they opened their laptop and started to deal with work-related information and communication. While this study was not explicitly focused on this issue, the authors suggest in the conclusions that further research on this issue may be needed. Churchill and Munro (2001) made a similar observation during their investigation about the locations where work was usually carried out by those engaging in nomadicity. More recent studies have noted similar phenomena: for example, Sadler et al's study of freelancers (2006), Ciolfi et al's interview study of ICT company managers (Ciolfi et al. 2012) and Lindley et al's (2012) study of web use for work and personal purposes.

Although celebrated by some workers, given the flexibility of the work tasks and the perceived possibility of making the most of both personal and professional lives, these changes are not so easy or welcome for some other workers (Duxbury and Smart 2011). Bean and Eisenberg (2006), for instance, investigated how people who were used to conduct work in a traditional fashion perceived changes in their work-life when their company decided to change its organisational scheme promoting nomadicity among their employees. The findings point out an ambivalent relationship between engaging in nomadicity and the blurring of work-life boundaries.

Many others note that by engaging in nomadicity workers can potentially have more flexible work-life arrangements and, therefore, engaging in nomadicity may increase job satisfaction and productivity (Chen and Nath 2005; Gluesing et al. 2008; Su and Mark 2008; Hislop and Axtell 2009). However, while such flexibility may be beneficial, it can be also overwhelming (Chen and Nath 2005; Bean and Eisenberg 2006; Mazmanian et al. 2006). People who engage in nomadicity are often prone to think that they must be available all the time and 
keep a high responsiveness rate (Lal and Dwivedi 2010). This leads to the need for renegotiation of the spatial-temporal boundaries regarding work and domestic life (Hislop and Axtell 2009). Some people even try to establish strict work-life boundaries, but they end up with crossing them accidentally (Salazar 2001; Lal and Dwivedi 2010; Duxbury and Smart 2011) and, sometimes, even developing a conflicting work-life balance relationship (Shumate and Fulk 2004; Chesley 2005).

Cousins and Robey's (2005) study illustrates some of the renegotiation done to conciliate work and domestic lives. As the study suggests, there comes a time where people want to draw the line between work and domestic spheres.

Although studies within the work-life boundary frame address nomadicity as something beyond a work condition, they usually do not address how the process permeates these two dimensions of life (de Carvalho 2013). In addition to that, these studies often develop a home/work life dichotomy and do not address the accomplishment of work in other locations (Hislop and Axtell 2007).

All these issues expose the need for research that advances the understanding of the notion of nomadicity.

\section{Deepening accounts of nomadicity}

As we have noted, nomadicity tends to be understood as a work condition characterised by the lack of a stable location where work is accomplished (Rossitto 2009), or a work strategy that encompasses the mobilisation of resources to distinct locations where temporary workplaces are established (Perry et al. 2001; Su and Mark 2008). A third perspective associates nomadicity with the technological infrastructure that allows people to access the informational and technological resources needed to accomplish their work on a anytime/ anywhere basis (Kleinrock 1996). And, finally, a fourth perspective analyses the blurring of work-life boundaries in the lives of people who engage with it (Salazar 2001; Meerwarth et al. 2008a).

Although these perspectives are highly relevant for the understanding of the notion of nomadicity, all these nuances must be simultaneously taken into account and delved into in order to understand nomadicity more thoroughly (as noted by de Carvalho (2013)). When the aforementioned frames are combined in a single lens to observe nomadicity as a complex phenomenon, the notions turn out as a dynamic process that emerges from people's engagement with an ecology of practices, involving a dialogue between human bodies and technologies as work gets accomplished in and across different sites (de Carvalho 2013). The complexity of such practices, where activities and processes are reconfigured according to the ways in which people think and strategize about their work and react to a number of influencing factors, demands for further empirical and conceptual investigations of the notion of nomadicity.

The articles included in this special issue significantly contribute to deepening the current understanding of nomadicity as a frame, as an ecology 
of practices and as a social, cultural and organisational condition of work. They also provide a nuanced account of how practices of nomadicity are performed by different actors: freelancers, students, public sector employees and corporation workers. Therefore, in these studies we see multiple configurations of movement, fluidity and nomadic identities, as well as an account of the complex motivations for nomadicity-instances of what Büscher in her contribution calls the "romance and reality of nomadic work" (Büscher 2014), where organisational and societal aspirations and demands interplay with personal and practical strategies for embracing and managing nomadicity.

Rossitto et al. present a study of people making sense of constellations of technologies in a nomadic setting. Their notion of "constellation" describes particular configurations of applications, devices and services available to nomadic users that become essential part of nomadic group practices. Constellations of technologies emerge and dissolve as needed, often in ways that are unique to a particular situation, assemblage of people and physical location: "The concrete instantiation [is] also determined by the people involved, their current activities and the specific technologies they brought to the group, which makes it difficult to predict whether an aligned constellation will reoccur in the same instantiation, and whether it will become a consolidated practice." (Rossitto et al. 2014).

The authors' description of how constellations of technologies are orchestrated and managed is entwined with an understanding of place, time and suitable working conditions. The vision of constellations as re-negotiated configurations of technological support questions the "'technological optimism' underlying the 'anytime, anywhere' vision of nomadic work" (Rossitto et al. 2014).

Liegl adopts a place focus in his study of freelance creative workers. His proposed lens - the care of place - identifies a nexus of practices linked to the motivations for movement (e.g. obligation vs. opportunity) that often for this particular category of workers have to do not with organizational and functional requirements but with the choice of moving in order to improve the process of creative work. In Liegl's study, the workers embrace nomadicity to accomplish solitary work, albeit often working in the presence of others-what Büscher (2014) identifies as the "working alone together" register of nomadicity. The author identifies how a particular combination of social, technical and atmospheric features of an environment is supportive of the affective and aesthetic side of nomadic work the creative freelancers enact. Such affective and aesthetic issues are equally practical and crucial to the freelancers' practices as the logistic and organizational aspects of nomadicity studied in past CSCW work (Liegl 2014). Moving themselves and their work apparatus from one place to another is essential for the creative freelancers not only as a way to rhythmically separate tasks, but also to find inspiration in their work.

In her paper, Humphry presents studies of two cohorts of nomadic workers (public servants at a local council office and employees of an ICT company) through the concept of "officing", which describes a form of infrastructure work 
mediating and structuring social relations (Humphry 2014). Humphry argues that officing is not only a frame to understand work practices, but also how the workers' sense of identity and professional self are constructed, linking the study of nomadic activities to broader issues of societal and cultural understanding of mobile work "including the casualisation and flexibilisation of labour, increased time pressure and transformation of the boundaries between work and life" (Humphry 2014).

Through connecting, configuring and synchronizing, nomadic workers realise officing as a practical approach to cope with the demands of mobility, including the "mobilisation work" (as defined by Perry and Brodie (2006)) that is often unseen by them and by employers, but also as a performative strategy of their identity of "ever-connected" workers: for example when participants describe replying to a query by text message or email, rather than with a phone call, to appear as if they were responding from the office rather than from another place. Humphry notes how the expectation of "ever-presence" for these workers is not confined to work, but extended to friends and family: thus, synchronizing becomes part of the strategy of coping with work and non-work demands of nomadic life.

These three papers further the reflection on the conceptual and practical understanding of nomadicity and contribute to the debate on the set of personal, organisational and cultural values associated with it, all of them arguing for the need to overcome the limited vision of nomadicity as "anytime, anywhere" work and to present a more holistic and dynamic set of phenomena.

The final two contributions to this special issue provide the broader contextualisation of nomadic practices within the wider social and economic context and within the CSCW tradition. In her invited paper, Barbara Czarniawska presents the working life-stories of nomadic workers indicating how this life plot is related to a number of matters, including labour market demands and generational perceptions of the necessity of embarking in nomadic professional lives. In particular, from recounting the lives of Anselm and Bernard, she states that their life plots do not exhibit "either the euphoria of freedom of choice nor the gloom of the forced movement" (Czarniawska 2014), but rather a complex "to-and fro-ing" linked to larger economic and societal concerns.

In her response to Czarniawska's article, Monika Büscher proposes a review of the multi-faceted phenomena surrounding nomadic work and of the tension between the "romantic" interpretations of nomadicity (as characterized either by freedom and fluidity, or by constant demands and dissolving organizational support mechanisms), and the actual conditions, demands and strategies of work in the "brave new world" of work on the move (Beck 2000).

Büscher argues that Czarniawska's focus on individual career choices rationalises and romanticises these choices and does not bring to the fore other powerful forces that shape nomadic lives, glossing over "an imbroglio of technology, social practices and intersecting social, physical, virtual, communicative and imaginative mobilities of nomadic work" (Büscher 2014). Büscher goes on to review key accounts of 
nomadicity and nomadic practices that have emerged in CSCW, identifying different registers of mobility: network society practices building social and cultural capital from the "weak ties" of frequent and lightweight social interactions; "plastic" amalgamation of technologies into everyday life practices; deliberate interactions underpinning collaborative interactions online; choosing and making places, and particularly - homing practices; different forms of remote and co-located solitary and cooperative activities ("working together apart" and "working alone together") (Büscher 2014).

The rich corpus of material offered by the five articles in this issue extends in several ways our understanding of nomadicity and goes beyond the categorisation of studies of nomadicity into frames that we used in this introduction to review prior nomadicity and mobility research in CSCW and related disciplines. It supports our view on the need to see nomadicity as a dynamic and emergent concept, where technologies, infrastructures, locations, organisational needs and constraints and personal strategies are intertwined in complex ecologies of practice. Rossitto et al.'s concept of "constellations" of technologies as particular assemblages of systems, devices and services to serve specific instantiations of nomadic collaborative work goes beyond a "system-centred" view and is entwined with understandings of collaborative practices, place-making and time management. Liegl's "care of place" and Humphry's "officing" are both constructs based on place, personal identity, motivational forces and technological mediation, as well as recognising the blurring between work and non-work in nomadic lives. Czarniawska's nomadic life story plots and Büscher's response articulating "registers" of nomadicity both extend the discussion to include wider social, economic and political issues around the romance and reality of nomadicity and mobility.

Overall, this special issue provides the $\mathrm{CSCW}$ community with an insight into the complexity of nomadicity in terms of motivations and practices, proposing the metaphor of "ecology" as a way to approach further studies of the multi-faceted set of constraints, opportunities and values that characterise nomadic work lives.

\section{Acknowledgments}

This publication stems from seminar proceedings and research activities within the "Nomadic Work/Lives in the Knowledge Economy" project sponsored by the Irish Social Science Platform (ISSP) with funds from Ireland's Higher Education Authority (HEA PRTLI) and EU Regional Development Funds, conducted by the special issue guest editors at the University of Limerick (Ireland) between 2008 and 2012. We are grateful to our project colleagues Breda Gray, Anthony D'Andrea and Lisa Wixted. We also thank all the JCSCW reviewers and the JCSCW Editor in Chief Kjeld Schmidt for their thoughtful feedback on the articles submitted to this special issue and on this editorial. 


\section{References}

Bean, C. J. and E. M. Eisenberg (2006). Employee Sensemaking in the Transition to Nomadic Work Journal of Organizational Change Management, vol. 19, no. 2, pp. 210-222.

Beck, U. (2000). The Brave New World. Cambridge: Polity Press.

Bødker, S., Kristensen, J. F., Nielsen, C. and W. Sperschneider (2003). Technology for Boundaries. In Proceedings of the 2003 International ACM SIGGROUP Conference on Supporting Group Work, Sanibel Island, USA. New York: ACM Press, pp. 311-320.

Bogdan, C., Rossitto, C., Normark, M., Adler, P. J. and K. S. Eklundh (2006). On a Mission without a Home Base: Conceptualizing Nomadicity in Student Group Work. In Hassanaly, P., Herrmann, T., Kunau, G. and M. Zacklad (eds): Cooperative Systems Design: Seamless Integration of Artifacts and Conversations. Amsterdam: IOS Press, pp. 23-38.

Breure, A. and J. van Meel (2003). AirportOffices: Facilitating Nomadic Workers. Facilities, vol. 21, no.7/8), pp. 175-179.

Brodie, J. and M. Perry (2001). Designing for Mobility, Collaboration and Information Use by Blue-collar Workers. SIGGROUP Bulletin, vol. 22, no. 3, pp. 22-27.

Brown, B. and K. O'Hara (2003). Places as Practical Concern for Mobile Workers. Environment and Planning, vol. 35, no. 9, pp. 1565-1578.

Büscher, M. (2014). Nomadic Work: Romance and Reality. A response to Barbara Czarniawska's 'Nomadic Work as Life Story-Plot'. CSCW Journal, vol. 23, no. 2, DOI 10.1007/s10606-0139194-6.

Chen, L. and R. Nath (2005). Nomadic Culture: Cultural Support for Working Anytime, Anywhere. Information Systems Management, vol. 22, no. 4, pp. 56-64.

Chesley, N. (2005). Blurring Boundaries? Linking Technology Use, Spillover, Individual Distress, and Family Satisfaction. Journal of Marriage and Family, vol. 67, no. 5, pp. 1237-1248.

Churchill, E. F. and A. J. Munro (2001). Work/place: Mobile technologies and Arenas of Activity. SIGGROUP Bulletin, vol. 22, no. 3, pp. 3-9.

Ciolfi, L. (2004). Understanding Spaces as Places: Extending Interaction Design Paradigms. Cognition, Technology \& Work, vol. 6, no. 1, pp. 37-40.

Ciolfi, L., Bartolucci, I. and D. Murphy (2005). Meaningful Interactions for Meaningful Places: Investigating the Relationships between Nomadic Work, Tangible Artefacts and the Physical Environment. In Proceedings of the 2005 Annual Conference on European Association of Cognitive Ergonomics. Athens: University of Athens, pp. 115-121.

Ciolfi, L., Fitzpatrick, G. and L. Bannon (2008). Settings for Collaboration: the Role of Place, Computer Supported Cooperative Work (CSCW), vol. 17, no.2-3, pp. 91-96.

Ciolfi, L., Gray, B. and A. D'Andrea (2012). Social Aspects of Place Experience in Nomadic Work/ Life Practices. In Dugdale, J., Masclet, C., Grasso, A. and J.-F. Boujut (eds): Proceedings of the 10th International Conference on the Design of Cooperative Systems, Marseille, 30 May-1 Jun 2012. London: Springer, pp. 183-196.

Coursaris, C. K. and D. J. Kim (2006). A Qualitative Review of Empirical Mobile Usability Studies. In Proceedings of the 12th Americas Conference on Information Systems. AIS Electronic Library.

Cousins, K. C. and D. Robey (2005). Human Agency in a Wireless World: Patterns of Technology Use in Nomadic Computing Environments. Information and Organization, vol. 15, no. 2, pp. 151-180.

Czarniawska, B. (2014). Nomadic Work as Life Story-Plot. CSCW Journal, vol. 23, no. 2, DOI 10.1007/s10606-013-9189-3.

Davis, G. B. (2002). Anytime/anyplace Computing And the Future of Knowledge Work. Communications of the ACM, vol. 45, no. 12, pp. 67-73.

De Boever, J. and D. De Grooff (2009). Activity Theory as a Framework for Contextual Inquiry: A Case Study. In Blashki, K. (ed): Proceedings of the IADIS International Conference Interfaces and Human-Computer Interaction, Algarve (Portugal), June 2009, pp. 78-86. 
de Carvalho, A. F. P. (2013). Technologically-mediated Nomadicity in Academic Settings: Tm- $N$ as a Dynamic and Emergent Process. Doctoral Thesis, University of Limerick, Limerick (Ireland).

de Carvalho, A. F. P., Ciolfi, L. and B. Gray (2011). The Making of Nomadic Work: Understanding the Mediational Role of ICTs. In Cruz-Cunha, M. M. and F. Moreira (eds): Handbook of Research on Mobility and Computing: Evolving Technologies and Ubiquitous Impacts. Hershey, PA, USA: IGI Global, pp. 381-396.

Demiris, A. M. and N. Ioannidis (2005). Context Awareness and Nomadic Devices Featuring Advanced Information Visualization in Clinical Routine. Journal of Telecommunications and Information Technology, vol. 4(2005). pp. 121-128.

Dourish, P. (2006). Re-space-ing Place: "Place" and "Space" Ten Years On. In Proceedings of the 2006 20th Anniversary Conference on Computer Supported Cooperative Work, Banff, Alberta, Canada. New York, USA: ACM, pp. 299-308.

Duxbury, L. and R. Smart (2011). The "Myth of Separate Worlds": An Exploration of How Mobile Technology has Redefined Work-Life Balance. In Kaiser, S., Ringlstetter, M. J., Eikhof, D. R. and M. Pina e Cunha (eds): Creating Balance?. Berlin and Heidelberg: Springer-Verlag, pp. 269-284.

Felstead, A., Jewson, N. and S. Walters (2005). Changing Places of Work. New York: Palgrave Macmillian. Gluesing, J. C., Meerwarth, T. L. and B. Jordan (2008). Patterns of Mobile Work and Life. In Meerwarth, T. L., Gluesing, J. C. and B. Jordan (eds): Mobile Work, Mobile Lives: Cultural Accounts of Lived Experiences. Malden, MA: Blackwell Publishing Inc., pp.148-155.

Goldmacher, A. (2008). Located Mobility: Living and Working in Multiple Places. In Meerwarth, T. L., Gluesing, J. C. and B. Jordan (eds): Mobile Work, Mobile Lives: Cultural Accounts of Lived Experiences. Malden, MA: Blackwell Publishing Inc., pp. 118-127.

Gorlenko, L. and R. Merrick (2003). No Wires Attached: Usability Challenges in the Connected World. IBM Systems Journal, vol. 42, no. 4, pp. 639-651.

Green, N. (2002). On the Move. Technology, Mobility, and the Mediation of Social Time and Space. The Information Society, vol. 18, no. 28, pp. 281-292.

Harper, R. (2003). People versus Information: The Evolution of Mobile Technology. In Chittaro, L. (ed): Mobile HCI 2003.Proceedings of the $5^{\text {th }}$ International Symposium. Berlin/Heidelberg: Springer, pp. 1-14.

Harrison, S. and P. Dourish (1996). Re-place-ing Space: the Roles of Place and Space in Collaborative Systems. In Proceedings of the 1996 ACM Conference on Computer Supported Cooperative Work, Boston, Massachusetts, USA. New York: ACM, pp. 67-76.

Harrison, A., Wheeler, P. and C. Whitehead (eds) (2004). The Distributed Workplace: Sustainable Work Environments. London and New York: Spon Press.

Hislop, D. and C. Axtell (2007). The neglect of spatial mobility in contemporary studies of work: the case of telework. New Technology, Work and Employment, vol. 22, no. 1, pp. 34-51.

Hislop, D. and C. Axtell (2009). To Infinity and Beyond?: Workspace and The Multi-location Worker. New Technology, Work and Employment, vol. 24, no. 1, pp. 60-75.

Humphry, J. (2014), Officing: Mediating Time and the Professional Self in the Support of Nomadic Work. CSCW Journal, vol. 23, no. 2, DOI 10.1007/s10606-013-9197-3.

Johansson, N., Lind, T. and B. Sandblad (2006). Usability in IT Systems for Mobile Work. In Andriessen, J. H. E. and M. Vartiainen (eds): Mobile Virtual Work: A New Paradigm?. Berlin/ Heidelberg: Springer, pp. 177-202.

Jordan, B. (2008). Living a Distributed Life: Multilocality and Working at a Distance. In Meerwarth, T. L., Gluesing, J. C. and B. Jordan, B. (eds): Mobile Work, Mobile Lives: Cultural Accounts of Lived Experiences. Malden, MA: Blackwell Publishing Inc., pp. 28-55.

Kakihara, M. and C. Sørensen (2001). Expanding the 'Mobility' Concept. ACM SIGGROUP Bulletin, vol. 22, no. 3, pp. 33-37.

Kakihara, M. and C. Sørensen (2004). Practising Mobile Professional Work: Tales of Locational, Operational, and Interactional Mobility. info, vol. 6, no. 3, pp. 180-187. 
Kakihara, M., Sørensen, C. and M. Wiberg (2002). Fluid Interaction in Mobile Work Practices. In Proceedings of the First Global Mobile Roundtable, Tokyo, Japan, May 29-30, 2002. Tokyo, Japan: Institute of Innovation Research.

Kindberg, T. and J. Barton (2001). A Web-based Nomadic Computing System. Computer Networks, vol. 35, no. 4, pp. 443-456.

Kleinrock, L. (1996). Nomadicity: Anytime, Anywhere in a Disconnected World. Mobile Networks and Applications, vol. 1, no. 4, pp. 351-357.

Kleinrock, L. (2001). Breaking loose. Communications of the ACM, vol. 44, no. 9, pp. 41-46.

Lal, B. and Y. K. Dwivedi (2010). Investigating Homeworkers' Inclination to Remain Connected to Work at "Anytime, Anywhere" Via Mobile Phones. Journal of Enterprise Information Management, vol. 23, no. 6, pp. 759-774.

Latour, B. (2007). Reassembling the Social: An Introduction to Actor-Network-Theory. New York: Oxford University Press.

Liegl, M. (2014). Nomadicity and the Care of Place - On the Aesthetic and Affective Organisation of Space in Freelance Creative Work. CSCW Journal, vol. 23, no. 2.

Lilischkis, S. (2003). More Yo-yos, Pendulums and Nomads: Trends of Mobile and Multi-location Work in the Information Society, Issue Report 36, IST Project STAR - Socio-economic Trends Assessment for the digital Revolution, June 2003. Bonn: empirica.

Lindley, S., Meek, S., Sellen, A., and R. Harper (2012). 'It's simply integral to what I do': Enquiries into how the web is weaved into everyday life. In Proceedings of the 2012 international conference on World Wide Web, International World Wide Web Conference, April 2012.

Luff, P. and C. Heath (1998). Mobility in Collaboration. In Proceedings of the 1998 ACM Conference on Computer Supported Cooperative Work, Seattle, Nov 14-18 1998. New York: ACM Press, pp. 305-314.

Lyytinen, K. and Y. Yoo (2002). Research Commentary: The Next Wave of Nomadic Computing. Information Systems Research, vol. 13, no. 4, pp. 377-388.

Makimoto, T. and D. Manners (1997). Digital Nomad. New York: John Wiley \& Sons.

Makimoto, T., Eguchi, K. and M. Yoneyama (2001). The Cooler the Better: New Directions in the Nomadic Age. Computer, vol. 34, no. 4, pp. 38-42.

Mark, G. and N. M. Su (2010). Making Infrastructure Visible for Nomadic Work. Pervasive and Mobile Computing, vol. 6, no. 3, pp. 312-323.

Mazmanian, M., Orlikowski, W. J. and J. Yates (2006). CrackBerrys: Exploring the Social Implications of Ubiquitous Wireless Email Devices. In Proceedings of the EGOS 2006. European Group for Organizational Studies Symposium.

Meerwarth, T. L. (2008). Disentangling Patterns of a Nomadic Life. In Meerwarth, T. L., Gluesing, J. C. and B. Jordan (eds): Mobile Work, Mobile Lives: Cultural Accounts of Lived Experiences. Malden, MA: Blackwell Publishing Inc., pp. 102-117.

Meerwarth, T. L., Gluesing, J. C. and B. Jordan, (eds) (2008a). Mobile Work, Mobile Lives: Cultural Accounts of Lived Experiences. Malden, MA: Blackwell Publishing.

Meerwarth, T. L., Gluesing, J. C. and B. Jordan (2008b). Tracking the Context of Mobile Lives. In Meerwarth, T. L., Gluesing, J. C. and B. Jordan (eds): Mobile Work, Mobile Lives: Cultural Accounts of Lived Experiences, Malden, MA: Blackwell Publishing, pp. 1-11.

Murphy, D., Bartolucci, I. and L. Ciolfi (2006). Understanding Real World Practices: a PlaceCentred Study of Mobile Workers. in Proceedings of the 2006 Mobile Interaction with the Real World Workshop, Espoo, Finland, Sep 122006.

Murray-Smith, R. (2009). Empowering People Rather Than Connecting Them. International Journal of Human Computer Interaction, vol. 1, no. 3, pp. 18-28.

Oulasvirta, A. and L. Sumari (2007). Mobile Kits and Laptop Trays: Managing Multiple Devices in Mobile Information Work. In Proceedings of CHI 2007, SIGCHI Conference on Human Factors in Computing Systems, San Jose, California, USA. New York: ACM, pp. 1127-1136. 
Perry, M. and J. Brodie (2006). Virtually Connected, Practically Mobile. In Andriessen, J. H. E. and M. Vartiainen (eds): Mobile Virtual Work: A New Paradigm?. Berlin/Heidelberg: Springer, pp. 97-128.

Perry, M., O’Hara, K., Sellen, A., Brown, B. and R. Harper (2001). Dealing with Mobility: Understanding Access Anytime, Anywhere. ACM Transactions on Computer-Human Interaction (TOCHI), vol. 8, no. 4, pp. 323-347.

Pica, D., Sørensen, C. and D. Allen (2004). On Mobility and Context of Work: Exploring Mobile Police Work. In Proceedings of the 37th Annual Hawaii International Conference on System Sciences, Hawaii, 5-8 Jan 2004. New York, USA: IEEE Computer Society, pp. 1-11.

Rossitto, C. (2009). Managing Work at Several Places: Understanding Nomadic Practices in Student Groups. Doctoral Thesis, Stockholm: The Royal Institute of Tecnology.

Rossitto, C. and K. S. Eklundh (2007). Managing Work at Several Places: A Case of Project Work in a Nomadic Group of Students. In Proceedings of the 14th European Conference on Cognitive Ergonomics, London, UK, Aug 28-31, 2007. New York: ACM, pp. 45-51.

Rossitto, C., Bogdan, C. and K.S. Eklundh (2014). Understanding Constellations of Technologies in Use in a Collaborative Nomadic Setting. CSCW Journal, vol. 23, no. 2, DOI 10.1007/s10606-013-9196-4.

Sadler, K., Robertson, T., Kan, M. and P. Hagen (2006). Balancing work, life and other concerns: a study of mobile technology use by Australian freelancers. In Proceedings of NordiCHI 2006.

Salazar, C. (2001). Building Boundaries and Negotiating Work at Home. In Proceedings of the 2001 International ACM SIGGROUP Conference on Supporting Group Work, Boulder, Colorado. New York: ACM Press, pp. 162-170.

Schmidt, K. and L. Bannon (2013). Constructing CSCW: the First Quarter Century. Computer Supported Cooperative Work, vol. 22, no. 4-6, pp. 345-372.

Shumate, M. and J. Fulk (2004). Boundaries and Role Conflict When Work and Family are Colocated: A Communication Network and Symbolic Interaction Approach. Human Relations, vol. 57, no. 1, pp. 55-74.

Sørensen, C. (2011). Enterprise Mobility: Tine Technology with Global Impact on Work. New York, USA: Palgrave Macmillian.

Sørensen, C.-F., Wang, A. and R. Conradi (2005). Support of Smart Work Processes in Context Rich Environments. In Krogstie, J., Kautz, K. and D. Allen (eds): Mobile Information Systems II, Boston: Springer, pp. 15-30.

$\mathrm{Su}$, N. M. and G. Mark (2008). Designing for Nomadic Work. In Proceedings of DIS 2008, the 7th ACM Conference on Designing Interactive Systems, Cape Town, South Africa, Feb 25-27, 2008. New York: ACM Press, pp. 305-314.

Vartiainen, M. (2006). Mobile Virtual Work-Concepts, Outcomes and Challenges. In Andriessen, J. H. E. and M. Vartiainen (eds): Mobile Virtual Work: A New Paradigm?, Berlin/Heidelberg: Springer, pp. 13-44.

Weiser, M. (1993). Ubiquitous Computing. Computer, vol. 26, no. 10, pp. 71-72.

Weiss, S. (2002). Handheld Usability. Hoboken, NJ: John Wiley \& Sons.

Wiberg, M. and F. Ljungberg (2001). Exploring the Vision of "Anytime, Anywhere" in the Context of Mobile Work. In Wiberg, M. (ed): In Between Mobile Meetings: Exploring Seamless Ongoing Interaction Support for Mobile CSCW, Umeå: Umeå University, pp. 112-128.

York, J. and P. C. Pendharkar (2004). Human-Computer Interaction Issues for Mobile Computing in a Variable Work Context. International Journal of Human-Computer Studies, vol. 60, no. 5-6, pp. 771-797. 